\title{
Evaluation of a telemedicine program in oral pathology and preventive oral examination in Hualqui Municipality, Chile.
}

\author{
Javiera Gonzalez ${ }^{1}$, Florencia Iglesias ${ }^{1}$, Carla Bancalari ${ }^{1 *}$, Ricardo Cartes-Velásquez ${ }^{2}$
}

\author{
1. School of Dentistry, Universidad de Concepción, \\ Concepción, Chile. \\ 2. Fundación Kimntrum, Concepción, Chile. \\ * Corresponding author: Carla Bancalari| Address: \\ Roosevelt 1550, Concepción, Chile. | Postal code: \\ CL 4070396. | E-mail: c_bancalari@hotmail.com. | \\ Phone: +56 998378362 . \\ Work received on 22/10/2020 \\ Revised work 10/02/2021 \\ Approved for publication on 18/02/2021
}

\begin{abstract}
Introduction: A telemedicine program in oral pathology (TOP) and a preventive oral examination (POE) to identify oral lesions was implemented in Hualqui, Chile. The objective of this study is to describe the results of the TOP plus POE strategy at CESFAM Hualqui, Chile, during the period of 2016 to 2019. Materials and methods: A prospective cohort study was conducted with 152 Hualqui patients between 2016 and 2019. The following variables were recorded: diagnosis; injury diagnosis dates; date of teleconsultation; date and response of the specialist and subsequent control; waiting time for response (WTR) and waiting time for attention (WTA). Results: The WTR was $19.7 \pm 12.8$ days and WTA presented a median of 20 days (1-125) days. A total of 45 different oral pathologies were identified, the most frequent being stomatitis $8.6 \%$ (13), fibroma $8.6 \%$ (13) and mucocele $7.9 \%(12)$, and among the least frequent highlights three cases of oral cancer. Conclusions: The waiting periods until a response from the specialist and then until the face-to-face control were around 3 weeks each, most of the cases were identified through POE and correspond mostly to benign pathologies.

KEY WORDS

Telemedicine; Oral pathology, Mouth neoplasms; Waiting lists.

Int. J. Inter. Dent Vol. 14(3); 226-228, 2021.
\end{abstract}

\section{INTRODUCTION}

Chile is in an epidemiological transition, characterized by an increase in chronic diseases and population aging, which has led to an increase in the consumption of medications and specialized healthcare ${ }^{(1)}$. In 2005, the AUGE/GES Plan was implemented, which prioritizes and guarantees by law healthcare for some diseases ${ }^{(2)}$. However, this caused pathologies not covered by GES/AUGE to lose priority, so the waiting lists to be attended to by specialists increased, both in quantity and in waiting time. One of the measures that the government applied to improve this situation was to generate the National Waiting Time Plan, which aims to reduce waiting times through various strategies, including the use of telemedicine ${ }^{(3)}$. This plan has managed to reduce waiting times significantly for various pathologies, associated with an increase in care through telemedicine from 817 in 2012 to 49,120 in $2017^{(3,4)}$.

The World Health Organization defines telemedicine as the delivery of health care services, where distance is a critical factor, by all health care professionals using information and communication technologies for the exchange of valid information for diagnosis, treatment and prevention of disease and injuries, research and evaluation, and for the continuing education of health care providers, all in the interests of advancing the health of individuals and their communities ${ }^{(5)}$. Telemedicine represents an innovative strategy that optimizes specialized human resources, complementing actions and solutions that allow the beneficiary population to experience a substantial improvement in access to healthcare ${ }^{(6,7)}$.

On the other hand, in 2001, the preventive medical examination (PME) was implemented, with the purpose of reducing the morbidity and mortality associated with those preventable or controllable diseases or conditions ${ }^{(3)}$. Recently, the preventive oral examination (POE) performed by a nurse or paramedic was included in PME to identify early oral mucosa lesions and refer them to a specialist. POE was implemented at CESFAM Hualqui and has generated a large number of referrals that have been attended through the telemedicine oral pathology (TOP) program.

Although the use of telemedicine has proven to be a useful strategy to improve and increase the number of services in various medical and dental specialties, there is little evidence of its use at the Chilean level. Therefore, the objective of this study is to describe the results of the TOP plus POE strategy at CESFAM Hualqui, Chile, during the period 2016 to 2019.

\section{MATERIALS AND METHODS}

A prospective cohort study was conducted with patients referred to TOP between August 2016 and May 2019 at CESFAM Hualqui, Chile. Ethical approval for this research was obtained from the Research and Bioethics Commission of the Faculty of Dentistry of the University of Concepción (C.E.C. $\left.N^{\circ} 9 / 18\right)$.

The population of interest were patients from the Hualqui commune who had an oral pathology and who were referred to the TOP program in the Guillermo Gran Benavente Hospital. The Guillermo Gran Benavente Hospital is the reference center for the entire Biobio region and is $25 \mathrm{~km}$ away from Hualqui. This population includes two groups, the first one comprise patients referred to TOP before starting the POE (August 2016 to October 2017), and the second one during the POE (November 2017 to May 2019).

The information was collected from the physical clinical files and through the SinetSur electronic health record system (Concepción Health Service, Chile). Every clinical file has attached an informed consent that explains what telemedicine consists of, which must be signed by the patient or responsible adult in case of being a minor, and by the professional who makes the initial diagnosis of the oral lesion.

The variables studied were: date of sending a teleconsultation by SinetSur; date of response from the specialist of the Guillermo Gran Benavente Hospital; date of the face-to-face control and place where the control will be carried out; definitive diagnosis; and whether the oral lesion was found during the POE.

The data were tabulated in a database made in Excel (MS Corp., USA) and then analyzed in InfoStat statistical software (InfoStat, Argentina). The waiting time from the teleconsultation was issued until the specialist responded with a diagnosis and steps to follow ("waiting time for response," WTR) and the waiting time from the specialist responding until the faceto-face control ("waiting time for attention,", WTA) was calculated in days. Descriptive statistics was generated using central tendency, absolute and relative distribution measures.

\section{RESULTS}

The final sample consisted of 152 patients. The WTR was $19.7 \pm 12.8$ days and its characterization per year is shown in Table 1 . On the other hand, the WTA presented a median of 20 days with an interval from 1 to 125 days; its characterization per year is shown in Table 2. The $68.4 \%$ 
(104) of the patients attended the face-to-face control, the majority of them (101) were treated at the Guillermo Grant Benavente Hospital, while the other three were treated at Hualqui.

Since November 2017, the date on which the POE was implemented, $91.7 \%(88)$ of the cases referred to TOP were started after POE. A total of 45 oral pathologies were identified, the most frequent being stomatitis $8.6 \%$ (13), fibroma $8.6 \%(13)$, mucocele $7.9 \%(12)$, hyperplasia $5.9 \%(9)$, cheilitis $5.3 \%(8)$, ulcer $5.3 \%(8)$, nevus $3.9 \%(6)$, thrush $3.3 \%(5)$, epulis $3.3 \%(5)$, cyst $3.3 \%(5)$, and others $44.7 \%(61)$. In others, three cases of oral cancer stand out.

Table 1: Waiting time for response in mean of days per year.

\begin{tabular}{c|c|c|c|c|c}
\hline Year & $\mathbf{n}$ & Mean & St. dev. & Min & Max \\
\hline 2016 & 18 & 31.6 & 12.3 & 9.0 & 62.0 \\
\hline 2017 & 45 & 10.3 & 8.5 & 1.0 & 45.0 \\
\hline 2018 & 73 & 22.3 & 11.9 & 6.0 & 71.0 \\
\hline 2019 & 16 & 20.4 & 10.9 & 8.0 & 44.0 \\
\hline Total & 152 & 19.7 & 12.8 & 1.0 & 71.0
\end{tabular}

Table 2: Waiting time for attention in median of days per year.

\begin{tabular}{c|c|c|c|c|c}
\hline Year & $\mathbf{n}$ & Median & Interquartile range & Min & Max \\
\hline 2016 & 14 & 42,0 & $27,0-67,0$ & 4,0 & 84,0 \\
\hline 2017 & 27 & 25,0 & $18,0-48,0$ & 3,0 & 90,0 \\
\hline 2018 & 54 & 16,5 & $11,0-35,00$ & 1,0 & 125,0 \\
\hline 2019 & 9 & 16,0 & $16,0-34,0$ & 13,0 & 52,0 \\
\hline Total & 104 & 20,00 & $13,0-42,0$ & 1,00 & 125,00
\end{tabular}

\section{DISCUSSION}

This study describes the results of the TOP plus POE strategy at CESFAM Hualqui, Chile, during the period 2016 to 2019; it is the first study carried out in Chile on this matter. The main results are that the waiting periods until a response from the specialist and then until the face-to-face check-up are around 3 weeks, periods that have been reduced over the years; most of the cases were started after POE; and most of the cases correspond to benign pathologies.

Telemedicine can be carried out in two modalities ${ }^{(8)}$. In real time or synchronous mode where live interaction allows direct communication from the treating doctor or other professional, patient and specialist; in this modality the patient may or may not be present. The other modality occurs in deferred time or asynchronous mode that allows the storage and transfer of data and still images, which are sent to a professional specialist along with the patient's medical history, so that the patient can be given a diagnostic and therapeutic orientation; in this modality, there is no direct personal interaction between the specialist and the patient. Among the main advantages ${ }^{(8-12)}$ of telemedicine we find: faster diagnoses and treatments; it avoids the discomfort of travel for patients and families; new possibilities of consulting with specialists; it promotes equity by taking care of isolated areas; it favors universality of access to healthcare; increases the efficiency of the system by optimizing resources and improving demand management; and increases the accessibility of information at all healthcare levels. While in the disadvantages ${ }^{(8-12)}$ we have: problems with privacy and confidentiality in the doctor-patient relationship; increased demand for specialists, and they may not be able to satisfy the high volume of patient care; dependence on a telecommunications infrastructure; risks linked to data security and management; and the need for extra time, even outside working hours, for its development or use.

Conventional specialty consultations take several months and even years ${ }^{(4)}$, which represents a risk if a patient presents a potentially malignant or malignant lesion ${ }^{(12)}$. That is why the need arose to implement new strategies, such as telemedicine. In Chile, in 2016 the first dental specialty was added, oral pathology ${ }^{(13)}$. Due to the recent application of this strategy, there are no reports to date on its use in Chile. However, several studies have proven the effectiveness of TOP in order to increase and accelerate the diagnoses ${ }^{(14-17)}$, and subsequently the treatment.

The average waiting time for the specialist to respond is approximately 3 weeks, as is the median waiting time for face-to-face care, which gives us approximately 6 weeks from when the interconsultation is sent until the patient attends the control. This is a substantial improvement compared with the results of the waiting lists for 2014 , where a significant proportion of patients waited more than a year ${ }^{(4)}$. Because the reception of the interconsultation is more expeditious than the traditional consultation, the specialist has the ability to immediately analyze the medical history and the attached photographs that are sent by the SinetSur platform, and if he or she suspects malignancy of the oral lesion assigns a priority time slot to that patient. According to telehealth reports from the Ministry of Health, since 2017 three health services started a pilot of Telemedicine with the aim at early detection of oral cancer: Concepcion, Ñuble and Arauco(18). The Concepcion Health Service started a pilot campaign on oral cancer detection though community activities and hiring an oral pathologist as TOP Manager in the Guillermo Grant Benavente Hospital. Since 2020, other health services in Chile have started access to telemedicince in oral pathology directed by Digital Hospital of Ministry of Health of Chile.

Because POE was only integrated into the PME in November 2017 the sample is still small, but it shows that the majority of referrals to TOP comes from POE. However, POE is not performed by a dentist, but rather by a nurse or paramedic, who may not have the necessary knowledge to carry out an adequate oral examination. For this reason, it is essential to train the personnel who will perform this exam, emphasizing its importance and the duty to consult a dentist in case of doubts or to examine something out of the ordinary.

With this study it was possible to determine the most prevalent pathologies in the Hualqui population, with stomatitis leading in first place, which coincides with other studies ${ }^{(19,20)}$. On the other hand, the incidence of malignant lesions was lower than other reports ${ }^{(15-17,19-21)}$.

Some limitations of this study are the small size of the sample analyzed and it was limited to a single commune. On the other hand, the diagnoses provided by the platform are not standardized, there being many variations of some diagnoses, added to nonspecific diagnoses such as "gum disease," thus making it difficult to perform reliable statistics.

\section{CONCLUSION}

The waiting period until a response from the specialist and then until the face-to-face control is around 3 weeks each; most of the cases were identified through POE and correspond mostly to benign pathologies.

\section{CONFLICT OF INTERESTS.}

The authors declare that there is no conflict of interests regarding the publication of this paper.

\section{FUNDING SOURCES.}

All authors have made substantive contribution to this study, and all have reviewed the final paper prior to its submission.

This paper has no funding sources. 


\section{References}

1. Matus-López M, Pedraza CC. Cost of a health care system for dependent older adults in Chile, 2012-2020. Rev Panam Salud Publica. 2014;36(1):31-6.

2. Cartes-Velásquez, R. Salud bucal en Chile, situación actual y desafíos futuros. Odontol Sanmarquina 2020;23(2):189-96.

3. Subsecretaría de Redes Asistenciales. Plan nacional de tiempos de espera No GES en Chile en modelo de atención en RISS (Redes Integradas de Servicios de Salud) 2014-2018. Chile: Ministerio de Salud; 2018.

4. Ministerio de Salud. Repositorio nacional de listas de espera marzo 2014. Chile; 2014.

5. World Health Organization. Telemedicine: opportunities and developments in member states. Report on the second global survey on eHealth. Geneva: World Health Organization, 2010.

6. Delgoshaei B, Mobinizadeh M, Mojdekar R, Afzal E, Arabloo J, Mohamadi E. Telemedicine: A systematic review of economic evaluations. Med J Islam Repub Iran. 2017;31:113.

7. Timpel P, Oswald S, Schwarz PEH, Harst L. Mapping the evidence on the effectiveness of telemedicine interventions in diabetes, dyslipidemia, and hypertension: an umbrella review of systematic reviews and meta-analyses. J Med Internet Res. 2020;22(3):e16791.

8. Cartes-Velásquez R, Bustos-Leal A. Teleodontología: Conceptos, experiencias y proyecciones. Odontoestomatología 2012;14(20):17-25.

9. Wootton R, Bonnardot L. Telemedicine in low-resource settings. Front Public Health. 2015; 3:3.

10. Adler-Milstein J, Kvedar J, Bates DW. Telehealth among US hospitals: several factors, including state reimbursement and licensure policies, influence adoption. Health Aff (Millwood). 2014; 33(2): 207-15.

11. Farahani N, Pantanowitz L. Overview of telepathology. Surg Pathol Clin.
2015;8(2):223-31

12. Castillejo JAP. Telemedicina, una herramienta también para el médico de familia. Aten Primaria. 2013; 45(3):129-32.

13. Subsecretaría de Redes Asistenciales. Programa nacional de telesalud en el contexto de redes integradas de servicios de salud. Chile: Ministerio de Salud; 2018. 14. Petruzzi M, De Benedittis M. WhatsApp: a telemedicine platform for facilitating remote oral medicine consultation and improving clinical examinations. Oral Surg Oral Med Oral Pathol Oral Radiol. 2016;121(3):248-54.

15. Carrard VC, Roxo Gonçalves M, Rodriguez Strey J, Pilz C, Martins M, Martins $\mathrm{MD}$, et al. Telediagnosis of oral lesions in primary care: The EstomatoNet Program. Oral Dis. 2018;24(6):1012-19.

16. Haron N, Zain RB, Nabillah WM, Saleh A, Kallarakkal TG, Ramanathan A, et al. Mobile phone imaging in low resource settings for early detection of oral cancer and concordance with clinical oral examination. Telemed J E Health. 2017;23(3):192-9. 17. Queyroux A, Saricassapian B, Herzog D, Müller K, Herafa I, Ducoux D, et al. Accuracy of teledentistry for diagnosing dental pathology using direct examination as a gold standard: results of the tel-e-dent study of older adults living in nursing homes. J Am Med Dir Assoc. 2017;18(6):528-32.

18. Ministerio de Salud de Chile. Plan nacional de telesalud. Santiago de Chile Ministerio de Salud de Chile, 2018.

19. Espinoza I, Rojas R, Aranda W, Gamonal J. Prevalence of oral mucosal lesions in elderly people in Santiago, Chile. J Oral Pathol Med. 2003;32(10):571-5.

20. Intapa C, Ayudhya CCN, Puangsombat A, Boonmoon B, Janyasurin T, Tonum $U$. Prevalence of oral mucosal lesions in geriatric patients living in lower Northern Thailand: a 10 years retrospective study. J Int Dent Med Res. 2017;10(3):868-71.

21. Bhatt S, Isaac R, Finkel M, Evans J, Grant L, Paul B, et al. Mobile technology and cancer screening: Lessons from rural India. J Glob Health. 2018;8(2):020421. 